\title{
Predicting Joint Replacement Waiting Times
}

\author{
Lauren E. Cipriano, Massachusetts General Hospital \\ Bert M. Chesworth, University of Western Ontario \\ Chris K. Anderson, Cornell University \\ Gregory S. Zaric, University of Western Ontario
}

\begin{abstract}
Currently, the median waiting time for total hip and knee replacement in Ontario is greater than 6 months. Waiting longer than 6 months is not recommended and may result in lower post-operative benefits. We developed a simulation model to estimate the proportion of patients who would receive surgery within the recommended waiting time for surgery over a 10-year period considering a wide range of demand projections and varying the number of available surgeries. Using an estimate that demand will grow by approximately $8.7 \%$ each year for 10 years, we determined that increasing available supply by $10 \%$ each year was unable to maintain the status quo for 10 years. Reducing waiting times within 10 years required that the annual supply of surgeries increased by $12 \%$ or greater. Allocating surgeries across regions in proportion to each region's waiting time resulted in a more efficient distribution of surgeries and a greater reduction in waiting times in the long-term compared to allocation strategies based only on the region's population size.
\end{abstract}

\section{Introduction}

Total hip and total knee replacement is a clinically-effective and cost-effective treatment for reducing joint pain and increasing quality of life [1-8]. In Ontario, total joint replacement of the hip or knee joint (TJR) is a universally insured service for which there is no "out-of-pocket" cost to the patient. Waiting for surgery is a form of non-price rationing common to publicly funded health care systems [9] and discussion of the acceptability of waiting times for total joint replacement surgery in Ontario occurred as early as the 1980s [10]. Currently, there is widespread concern as to whether patients in Ontario are able to access TJR surgery within a clinically acceptable time frame [11-19].

Between 2001 and 2005, the median time between the date the decision to have surgery was made and the date of surgery increased $14 \%$ in Ontario [16, 17]. Several expert groups have recommended that patients should not wait longer than 6 months for TJR surgery [18, 20-22]. In 2005, 
however, fewer than half of all TJR surgeries were provided within the recommended maximum waiting time of 6 months and $25 \%$ of patients waited more than 1 year for surgery [17]. Wide variation in the TJR waiting times across Ontario have been reported, such that the median waiting time is twice as long in the region with the longest waiting times as it is in the region with the shortest waiting times [17]. Additionally, before the decision to have surgery is made, patients must wait for the initial consultation with an orthopedic surgeon following referral. In Ontario, the median waiting time from referral to first consultation has been reported to be $2-3$ months $[23,24]$.

Demand for TJR is partly controlled by primary care physicians, but increases in demand are primarily due to factors external to the health care system such as population demographics $[25,26]$, socioeconomic factors [27-29], increasing rates of obesity [30-34], shifting disease patterns [35], shifts in clinical criteria [26, 35-38], presence and type of insurance coverage [39-46], and the willingness of patients to undergo surgery [27, 47]. In Ontario, the annual supply for TJR surgeries is centrally determined by the Ministry of Health and Long Term Care (MOHLTC) and distributed to the hospitals that provide TJR surgery. There is no formal method connecting the decisions surrounding increases in supply for surgery to the factors that cause increases in demand.

Long waiting times for TJR surgery impact quality of life $[38,48-50]$. Some studies indicate that quality of life decreases and pain increases while waiting for surgery [49-54]. In addition to quality of life consequences, there are social consequences to waiting for TJR surgery including reduced or modified work $[50,55,56]$, prolonged pre- and post-operative sick leave, job loss, and a reduced possibility of returning to work post-operatively [55-57]. Patients who wait longer for surgery are less likely to ever return to work even when the most severe patients receive surgery first [55]. Waiting longer for surgery has been shown to reduce the magnitude of improvement from surgery $[20,58]$.

The federal and provincial governments in Canada are discussing potential strategies to address waiting times and they have implemented a "10 year plan to strengthen health care" by increasing the number of health professionals, clearing backlogs, building capacity, improving community care, and developing tools to manage waiting times [59]. Despite this landmark agreement many questions remain: how many health professionals are needed and of what type? How many surgeries will be required to clear the backlog? How big is the backlog? How much capacity is needed and by when? What types of 'tools' will be considered and how will they be evaluated? It has been observed that “operational research models have been largely absent from the current debate on wait times in Canada"[9]. We attempt here to use registry data and a simulation model to answer some of these critical questions. 
We built a simulation model in which queuing for TJR was modeled as 25 parallel queues. We report the results of the waiting times relative to an important clinical threshold as an average across all the queues. We used the simulation model to determine the number of surgeries that would need to be performed each year to meet specific waiting time targets and improve equity in waiting across the regions of the province. Factors that affect queue performance were identified and queue parameters were set using information available from the Ontario Joint Replacement Registry (OJRR) database, the MOHLTC, and from secondary sources.

The structure of the paper is as follows: In Section 2, we present a brief literature review. In Section 3, we present the data used and the structure of the simulation model. In Section 4, we present the results of the "what if" scenarios and in Section 5, we provide some concluding remarks.

\section{Literature Review}

The behavior of GI/G/1 queues under the constraints of heavy traffic (quantified by the ratio, $\rho$, of the arrival rate to the service rate approaching 1) was first characterized by Kingman who showed that the mean waiting time multiplied by $(1-\rho)$ in a heavy traffic situation is approximately exponentially distributed $[60,61]$. This work was furthered by Kollerstrom who demonstrated that this finding could be extended to $\mathrm{Gl} / \mathrm{G} / \mathrm{s}$ queues when $\mathrm{s}>1$ [62] and by Mazumar who demonstrated that this finding could be extended to queues with more than one type of customer treated in priority sequence [63]. The definition of "heavy traffic" was expanded by Iglehart and Whitt [64] and Whitt [65] to include situations in which $\rho$ was greater than or equal to 1 . Their work further extended the body of heavy traffic situations under which the expected waiting time could be characterized by an exponential distribution. The application of this work was further expanded when Dagsvik demonstrated that the same could be said for Gl/G/1 bulk service queues in which late arrivals were not allowed to join the service group [66].

Heavy traffic queues and more specifically queues with periods of heavy traffic are common in public health care as they are believed to be evidence of high efficiency. The consequences of a long queue and balking customers in health care is different than other applications, as the consequences of long waiting or balking are not best measured in monetary denominations but instead as a heath care problem not addressed [67] or as life-years or quality-adjusted life-years lost [51, 54, 68]. Mathematical modeling is well suited to address the issues of health care resource planning [69-71]. Queuing theory has been applied to many aspects of heath care including emergency rooms [72, 73], cardiac catheterization [74], drug treatment [75], organ transplantation [76-79], and total joint replacement 
[35]. For more examples and a more detailed description the reader is referred to one of the many reviews in this area [80-84].

The queue for total joint replacement in Ontario is unstable $(\rho>1)$, long (over 25,000 patients waiting) and has long waiting times (more than half of patients wait longer than clinically advisable). The number of surgeries that need to be provided each year to reduce the expected waiting time to within a clinically acceptable time frame is unknown. Further, as the total joint replacement system is a series of queues running in parallel (each surgeon manages his or her own waiting list), a method of distributing service capacity across the servers is required such that equity in expected waiting time across the parallel queues can be achieved.

\section{Application to Total Joint Replacement in Ontario}

\section{Model Overview}

The MOHLTC has divided the province of Ontario into 14 regions called Local Health Integration Networks (LHINs) for planning purposes [85]. For the purposes of the simulation model, we divided the province of Ontario into 25 regions: 11 teaching hospitals and 14 groups of community hospitals representing the 14 LHINs less any teaching hospitals within each LHIN. A map of Ontario identifying the LHINs and the locations of the teaching hospitals is in Fig. 1. Teaching hospitals were treated as independent regions because they see a different case-mix of patients than those seen by community hospitals, including larger portions of complex cases and higher priority patients. All patients came from a LHIN $i$, where $i=1, \ldots, 14$, and received surgery in a region $j$, where $j=1, \ldots, 14$ represent regions of community hospitals and $\mathrm{j}=15, \ldots, 25$ represent teaching hospitals. The simulation began on March 31 , 2005 with the starting parameters summarized in Table 1. All notation and model equations are summarized in Table 2.

The simulation advanced in one-month intervals for 120 months, ending on March 31, 2015. Each month the following actions occurred in sequence for each region: (1) the number of patients who decided to have surgery and the number of surgeries allocated to each region were determined; (2) new patients were added to the end of the waiting list; (3) patients on the list were sorted based on clinical severity and length of time they have already waited; and (4) the patients at the top of the list were removed. The number of patients removed from the waiting list in step 4 was the lesser of the total number of patients waiting for surgery in the region and the number of surgeries allocated to that region that month. Each patient's waiting time was calculated when they were removed from the 
waiting list. There are a number of stochastic elements in this simulation model which affect monthly demand, monthly surgical volumes, generation of patient characteristics including patient priority, and the position patients are initially assigned on the waiting list. A flow chart of the simulation is provided in Fig. 2.

We assumed that each total hip replacement and each total knee replacement consumed one surgery unit. A primary surgery (the first time a joint is replaced) takes less time to complete and consumes fewer resources than a revision surgery (a second joint replacement surgery on a failed previously replaced joint). However, we assumed that primary and revision surgeries were equally resource intensive in the simulation, each consuming one surgery unit because the provincial government does not specify what proportion of surgeries must be primary or revision joint replacements.

Queue performance indicators, such as the waiting time distribution and the length of the waiting list were collected at the end of each simulated year for all patients and for patient subgroups (i.e., high vs. low priority patients). The model was built in a spreadsheet using Visual Basic for Applications or VBA (Excel 2003, Microsoft). Each scenario was repeated 100 times using common random numbers [86] and the data reported here are the average of all 100 simulations.

Throughout the development of the model we met with a research advisory board consisting of surgeons and policy makers. The model was refined until all stakeholders agreed that it represented a reasonable simplification of the current situation. The following sections provide additional detail with respect to the model design and assumptions.

\section{$\underline{\text { Data Sources }}$}

The Ontario Joint Replacement Registry (OJRR) was a clinical registry that collected patient information on a voluntary basis from orthopedic surgeons in Ontario from 2001 to 2005 . The information included patient demographic (i.e., gender, age, postal code) and personal medical information (i.e., body mass index, specific diagnosis), surgical information (i.e., primary joint replacement or revision surgery, hip or knee replacement, unilateral or bilateral), and specific information about the prosthesis (i.e., brand, material, bar code). The OJRR also collected the date the referral for consultation was received by the orthopedic surgeon, the date of the first orthopedic consultation, the date that the surgeon and patient decided to proceed with total joint replacement surgery and the date that surgery occurred. 


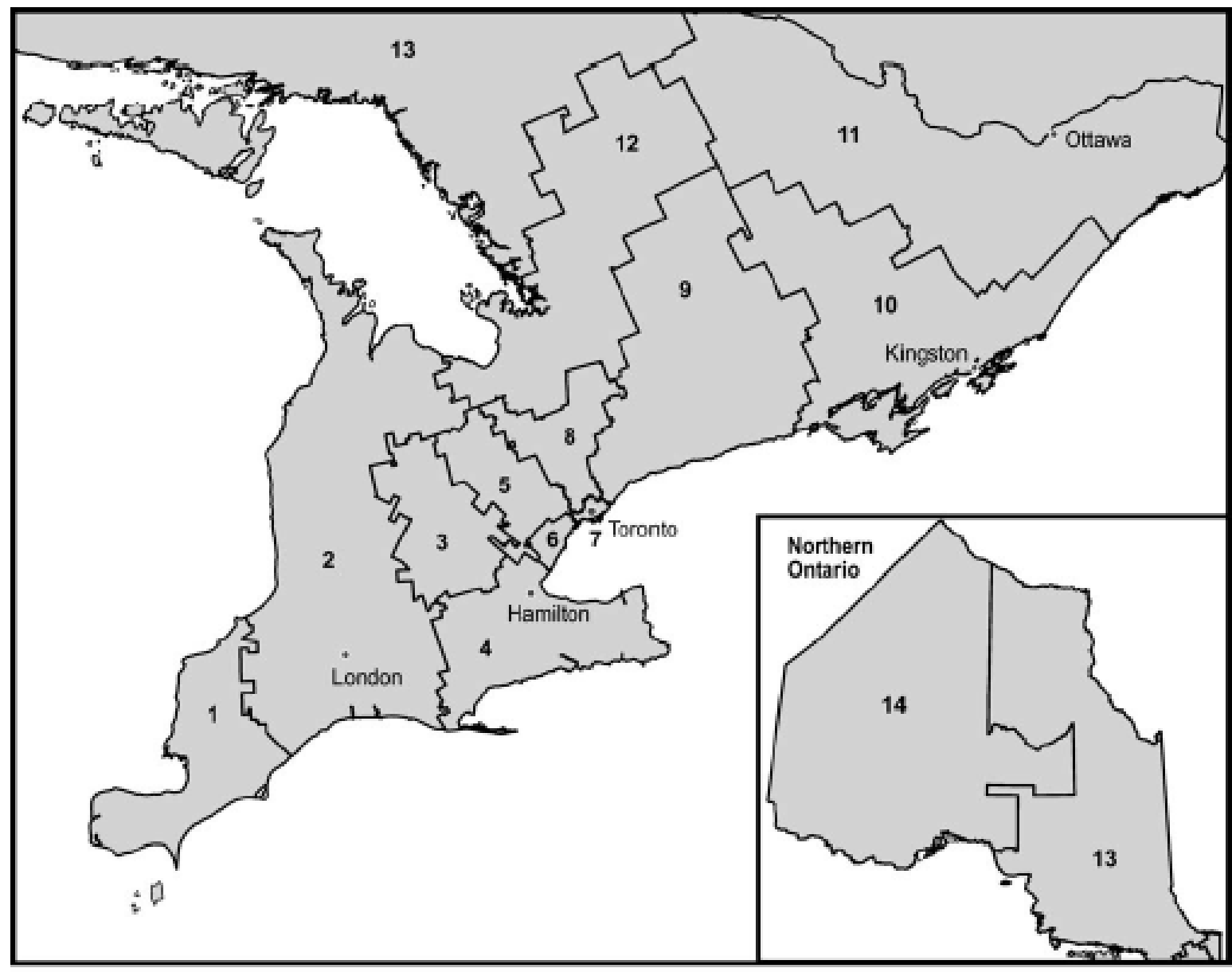

\section{Local Health Integration Networks (LHINs)}

1. Erie St. Clair

2. South West

3. Waterloo Wellington

4. Hamilton Niagara Haldimand Brant

5. Central West

6. Mississauga Oskville

7. Toronto Central
8. Central

9. Central East

10. Scuth East

11. Champlain

12. North Simcoe Muskoka

13. North East

14. North West

\section{Teaching Hospitals}

London

Londen Heam Sciences Cendre

St. Joseph's Heath Care

Hamilton

Hamiton Healh Sciences

Carporstion

St. Josoph's Heatth Care

Kingston

Kingehn Genaral Hocpitai
Toronto

Mount Sins Hasplad

St. Wichael's Hospital

Sumyorook and Women's Calloge Health Saiences Contre University Heaith Netwark

Ottawa

Otrawa Hospies Carparation Hopatal Montfart

Fig 1 A map of Ontario, Canads, identifying the Local Health Integnticn Networks and the bocation of texhing haspitals. Map provided by the hrsitute for Clinical Evahative Sciences, Toronto, Ontario, Canada

The OJRR provided us with 28,998 eligible patient records for individuals who received surgery between April 2002 and March 2005 and 13,123 eligible records of patients who were waiting for surgery in March 2005. Records were ineligible if they had invalid or missing date fields (184 records; less than $1 \%$ of the total number) or if the patient waited longer than 2.5 years between decision to have surgery and surgery or between referral to an orthopedic surgeon and surgery $(2,144$ records; $4.8 \%$ of the total number). Consistent with the policy of the OJRR, this latter group of patients was excluded 
because they were presumed to have a date field error or in the case of individuals who were still waiting for surgery, that they may have died, received the surgery elsewhere, or were no longer eligible for surgery.

Talik 1 Sewulasos sarieg wises

\begin{tabular}{|c|c|c|c|c|c|c|}
\hline \multicolumn{2}{|c|}{$\begin{array}{l}\text { Loeal Heals } \\
\text { laxegroba Netwoek }\end{array}$} & \multirow{2}{*}{$\begin{array}{l}\text { Number of Pacieas } \\
\text { Wuich os } \\
\text { Maxh } 31,2005 \\
753\end{array}$} & \multirow{2}{*}{$\begin{array}{l}\text { Areage Moadly Nimber } \\
\text { of 1edivibula Eigble } \\
\text { is } 20042005 \\
2,215\end{array}$} & \multirow{2}{*}{ 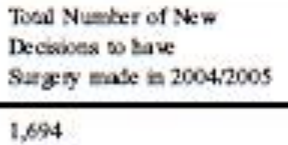 } & \multirow{2}{*}{ 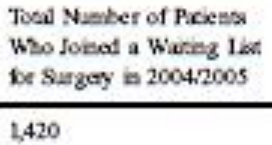 } & \multirow{2}{*}{$\begin{array}{l}\text { Todal Nuenber of } \\
\text { Sugerixen Pefarmat } \\
\text { is } 20042005^{*} \\
1,277\end{array}$} \\
\hline 1 & Fiso-St. Chir & & & & & \\
\hline \multirow[t]{4}{*}{2} & Soub Wes: & & 4,221 & 2,37 & & \\
\hline & IHIN 2 coenennizy boopirils & 1,175 & & & 1,200 & 1,196 \\
\hline & Lodoa Heats Sosesoes Cesse" & 2077 & & & 2032 & 1,023 \\
\hline & 8. Josps's Heava Cre, losbo" & 132 & & & 237 & 235 \\
\hline 3 & Water bo Wellingon & 1,232 & 2,187 & 1,362 & 2612 & 1,438 \\
\hline \multirow[t]{4}{*}{4} & Hamibes Nigas Haldemaad Bries & & 4,347 & 3,526 & & \\
\hline & LIN 4 coenew niry boopiouls & $\$ 190$ & & & 1396 & 1,653 \\
\hline & 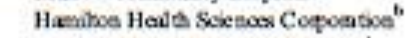 & 2070 & & & 2847 & 1,044 \\
\hline & 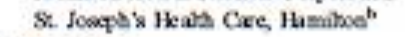 & 444 & & & 350 & 420 \\
\hline 5 & Censal Wex: & 672 & 1,332 & 1,599 & 960 & $6 \pi$ \\
\hline 6 & Msorbechega Hahos & 1,534 & 2,363 & 1,849 & 1,642 & 1,668 \\
\hline \multirow[t]{6}{*}{7} & Tcosess Cestral & & 1,824 & 1,729 & & \\
\hline & LHN 7 coementisy borposils & 364 & & & 735 & 364 \\
\hline & Moues Siani Hoopiod" & 398 & & & 515 & 330 \\
\hline & 8. Mxtael's Hoopiat" & 6) & & & 543 & 760 \\
\hline & $\begin{array}{l}\text { Suenybook asd Woesen'x } \\
\text { College Heal th Sciencen Cense" }\end{array}$ & 1719 & & & 2,375 & 1,575 \\
\hline & Uaresity Heal:a Nerwod" & 298 & & & Q1 & 681 \\
\hline 3 & Censal (York) & 2065 & 4,786 & 2,940 & 2429 & 2,322 \\
\hline 9 & Central Fa: & 2904 & 6,062 & 3,294 & 1370 & 2,809 \\
\hline \multirow[t]{3}{*}{10} & Sous Fast & & 2,778 & 2,173 & & \\
\hline & 1.HON 10 coenewirgy roopials & 480 & & & 904 & 306 \\
\hline & Kington Geseral Hoppiat" & 1,536 & & & 3,111 & 396 \\
\hline \multirow[t]{4}{*}{11} & Complais & & 4,364 & 2,957 & & \\
\hline & LHN II coenevingy boxpials & 653 & & & कs & 630 \\
\hline & Otarwa Hospial Capoeasod" & 1,467 & & & 1,062 & 1,232 \\
\hline & Hopial Matfoe" & $\$ 2$ & & & 649 & 507 \\
\hline 12 & Norta Sinose Musibia & 83 & 1,772 & 1,442 & 23 & 730 \\
\hline 13 & Noeth Fass & 1,240 & 3,126 & 2,826 & 1,571 & $1,0,52$ \\
\hline \multirow[t]{2}{*}{14} & North Wext & 1,534 & 1,371 & 1,153 & 1,149 & 563 \\
\hline & Tood Oxaso & 26,583 & 43,751 & 31,443 & 31,443 & 26,443 \\
\hline
\end{tabular}

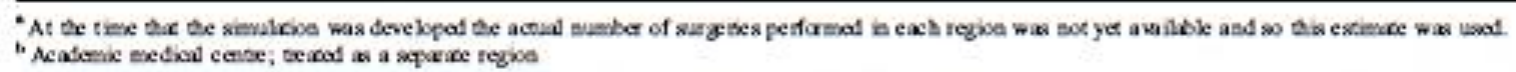

The OJRR also provided us with estimates of how complete the registry was relative to the known number of surgeries performed at each hospital in each year, shown in Table 3. These fiscal year and location-specific completion rates were used to estimate the actual number of patients who made decisions to have surgery, the number of patients who were waiting for surgery at any point in time, and the proportion of patients who traveled from one region to another for surgery each year. A complete, audited list of patients waiting for TJR surgery in Ontario does not exist so there was no list to compare against the OJRR waiting patient list. We assumed that patients who had not yet received surgery were representative of waiting patients based on the fiscal year they decided to have surgery.

Other information for the base case simulation and model validation were acquired from published reports of waiting times and the volume of surgeries provided in Ontario $[16,17]$. We 
obtained decision-to-surgery waiting times for each teaching hospital in the province from the Institute for Clinical Evaluative Sciences (ICES) and we obtained the number of surgeries allocated to each region in 2004/2005 from the MOHLTC.

Age-specific rates for patient access to surgery (access) and willingness to consider surgery (willingness) were obtained from the author of several studies of willingness for TJR surgery among eligible candidates in two counties in Ontario $[27,47,87,88]$. The studies only included data on individuals over the age of 55 . In order to simulate patients over the age of 45 , individuals in the $45-49$ and 50-54 age groups were assumed to have the same willingness to consider surgery and access to surgery as individuals aged 55-59 years. Patients between the ages of 18-45 years and patients over the age of 89 were not modeled. In 2004/2005, however, these patient groups represented only 2.3 and $0.3 \%$ of patients receiving TJR surgery, respectively.

\section{Model Description}

\section{Patient Types and Prioritization}

Many clinical expert groups recommend that patients with more severe symptoms should receive joint replacement before patients with less severe symptoms. However, there is no consistent method of categorizing patients, nor is there consensus of how to implement prioritization policy into clinical practice [18, 21, 89-95]. For the purposes of this simulation model, we categorized patients into three levels of severity based on the newly created OJRR prioritization guidelines [20].

Of the 28,998 eligible patient records in the OJRR database, there were 9,268 patients who participated in additional surveys which assessed their role, independence, and pre-operative disability (collected within 28 days of their decision to have surgery) using the Western Ontario and McMaster Universities Osteoarthritis Disability Index (WOMAC) score [96]. The decision logic for classifying these patients into three levels of clinical urgency is outlined in Fig. 3. These records were organized into two patient tables, one for community hospitals and one for teaching hospitals to maintain the case-mix differences.

\section{Generation of Patients}

Patients in the starting waiting list and new patients joining the list in the simulation were randomly assigned the patient characteristics of the historical patients including patient age, severity, priority level, joint requiring surgery, whether the surgery required was a primary or revision joint replacement, whether the patient had a previous total joint replacement on a different joint, whether 
the patient had traveled to outside of their own LHIN to obtain surgery, and how long the patient waited between referral to an orthopedic surgeon and making the decision to have surgery.

\section{The Initial Number of Waiting Patients}

We estimated the number of patients waiting at the end of each month between April 2002 and March 2005 based on the number of patients in the OJRR database who had made a decision to have surgery and who had not yet received their surgery for each month. We adjusted this number for regional and fiscal-year data completion as described above. We estimated the number of patients waiting for surgery on March 31, 2005 for 23 of the 25 regions using the average number of patients waiting at the end of each month between April 2004 and March 2005.

Two teaching hospitals, representing two regions in the simulation, had completion rates of less than $11 \%$. To estimate the number of patients waiting for surgery at these two facilities, we developed a regression equation $\left(R^{2}=0.64, p=0.079\right)$ relating the volume of surgeries provided in $2004 / 05\left(P S_{j, 0}\right)$ and the median waiting time for surgery (MedianWaiting Time $e_{j}$ ) to the number of patients waiting for surgery $\left(W L_{j, 0}\right)$ when $j \geq 15$ :

$$
W L_{j, 0}=-450.9+1.32 \times P S_{j, 0}+31.2 \times{\text { MedianWaiting } \text { Time }_{j}}
$$

The regression equation was developed using the estimated number of patients waiting for surgery at eight of the nine other teaching hospitals. The median waiting time for each teaching hospital in fiscal year 2003/2004 was provided by ICES; fiscal year 2004/2005 waiting times were not available at the time the model was developed.

To generate a list of patients with approximately the estimated number of patients waiting in each region, we ran the base case simulation starting with no waiting patients in year 2000 for 5 years. This produced a waiting list of 26,583 patients distributed across each of the 25 regions and ordered as if the OJRR prioritization tool had been used consistently each year since 2000 . By generating the initial list in this way we ensured that any changes to the list early in the simulation time horizon would be the result of changes in supply and demand only and not changes in patient prioritization. We performed sensitivity analysis on the length of the starting waiting list. 


\section{Adding New Patients to the Waiting List}

The waiting list in each region was numbered from 1, representing the top of the list, to the total number of patients on the list. To simulate current prioritization behaviors, each new patient was assigned an initial position on the regional queue based on the distribution of waiting times for each 
priority level within that region. When new patients arrived on the list their position could be better than that of existing patients for two reasons: (1) they were in a higher clinical priority group; or (2) they were in the same clinical priority group but were assigned a better initial position. The random assignment of initial positions was necessary to replicate the waiting time distributions observed at the regional level because individual surgeons prioritize their own lists. Even if each surgeon prioritized solely on a clinical basis, the regionally aggregated list would not be sorted based on clinical priority because the case-mix of each surgeon is different (i.e., some surgeons have proportionally more high priority patients than other surgeons). Each month, the patients moved up the list as other patients were removed.

The Rate of New Decisions to Have Surgery

We estimated the number of decisions to have surgery each month between April 2002 and March 2005 for 23 of 25 regions using the decision dates of patients recorded in the OJRR database and adjusting for completion. We assumed that the numbers of new decisions to have surgery each month in each of the two remaining regions were proportional (based on the number of surgeries performed annually) to that at a third similar hospital.

We estimated that the number of decisions to have surgery were $29,227,31,443$, and 36,669 in 2002/2003, 2003/2004, and 2004/2005, respectively. In March 2005, the MOHLTC made funding contingent on the submission of waiting time information to the OJRR, which may have artificially inflated the 2004/2005 estimates for number of new decisions. Therefore, in the base case simulation, the number of new decisions in $2004 / 2005$ was assumed to be 31,443 . 
Fig 2 A flow chart of the procedures in the simulation model that occur each month

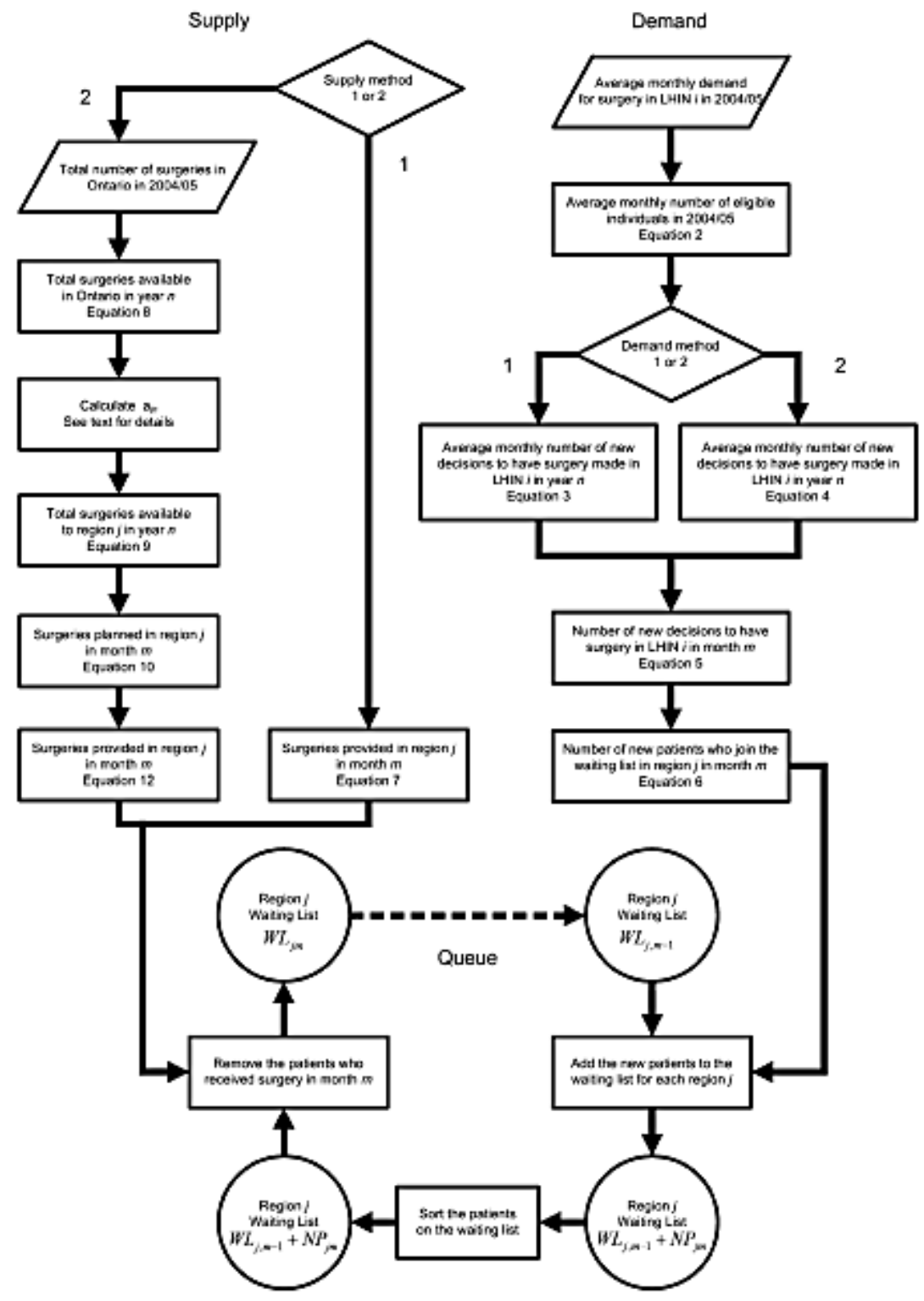

The Number of Individuals Eligible for Surgery in 2004/2005

We estimated the average monthly number of individuals eligible for surgery in each LHIN $\mathrm{i}$, where $\mathrm{i}=1, \ldots, 14$ in $2004 / 2005$ ( Need $_{i}$ ) based on the average monthly number of new decisions to have surgery in 2004/2005 $\left(D_{i, 0}\right)$, the age distribution of patients who received surgery in 2004/ $2005($ AgeS $k)$, willingness to have surgery $\left(W_{k}\right)$ and access to surgery $\left(A_{k}\right)$ where

(2)

$$
\text { Need }_{i}=D_{i, 0} \times \sum_{k=1}^{9} \frac{\text { AgeS }_{k}}{W_{k} \times A_{k}} \text {. }
$$


Estimating the Number of New Decisions to Have Surgery Each Month

We estimated new decisions at the level of the LHIN, $i=1, \ldots, 14$. In all cases demand increased from the average monthly number of new decisions estimated to have occurred in 2004/2005 ( $D_{i, 0}$, in Table 1). We used two methods to estimate increase in demand over time. In method 1 , annual demand from each LHIN $\left(D_{i, n[m]}\right)$ increased by a pre-determined rate $(x)$ ranging from 0 to $15 \%$. We used this method to determine the behavior of the waiting list at fixed ratios of supply and demand. In method 2, we estimated the rate at which demand may increase in each region using demographic and other information. We used method 2 as the base case estimation for future demand in the Ontario TJR system.

(3)

Method $1: D_{i, n[m]}=D_{i, n[m]-1} \times(1+x)$

Method $2: D_{i, n[m]}=$ Need $_{i} \times \operatorname{AgeR}_{i, n} \times(1+g)^{n}$

(4)

$$
\times \sum_{k=1}^{9} \operatorname{AgeN}_{k} \times W_{k} \times A_{k}
$$

In method 2, the number of new decisions to have surgery increased annually according to two factors: (1) the number of people over the age of 55 in LHIN $i$ in year $n$ compared to the number of people over the age of 55 in LHIN i in $2005\left(A g e R_{i, n}\right)$; and (2) an estimate that willingness to consider surgery will increase at $5 \%$ per year $(g=0.05)$. The number of people over age 55 in each LHIN in 2005 was estimated using MOHLTC population estimates [85], Ministry of Finance population estimates, and the approximate boundaries for LHINs by census divisions [97, 98]. Projections for the population of each LHIN in years 2006 through 2015 were estimated using the Ministry of Finance population estimates and the approximate boundaries for LHINs by census divisions $[97,98]$. 
Table 3 Completion of the Ontario Joint Replacement Registry data set relative to the total number of surgeries provided as reported by the Ministry of Health and Long Term Care

\begin{tabular}{|c|c|c|c|c|}
\hline \multirow[b]{2}{*}{ LHIN } & \multirow[b]{2}{*}{ Region } & \multicolumn{3}{|l|}{ Completion Rate } \\
\hline & & April 2002-March 2003 & April 2003-March 2004 & April 2004-March 2005 \\
\hline 1 & LHIN 1 Total & $66.7 \%$ & $70.3 \%$ & $85.2 \%$ \\
\hline \multirow[t]{4}{*}{2} & LHIN 2 community hospitals & $47.8 \%$ & $67.2 \%$ & $61.1 \%$ \\
\hline & London Health Sciences Centre ${ }^{a}$ & $62.1 \%$ & $78.5 \%$ & $78.1 \%$ \\
\hline & St. Joseph's Health Care, London ${ }^{2}$ & $59.8 \%$ & $60.0 \%$ & $69.4 \%$ \\
\hline & LHIN 2 Total & $55.7 \%$ & $71.5 \%$ & $69.0 \%$ \\
\hline 3 & LHIN 3 Total & $36.1 \%$ & $42.9 \%$ & $45.7 \%$ \\
\hline \multirow[t]{4}{*}{4} & LHIN 4 community hospitals & $32.4 \%$ & $38.8 \%$ & $41.9 \%$ \\
\hline & Hamilton Health Sciences Corporation ${ }^{2}$ & $9.4 \%$ & $8.4 \%$ & $10.4 \%$ \\
\hline & St. Joseph's Health Care, Hamilton ${ }^{2}$ & $46.8 \%$ & $52.8 \%$ & $62.1 \%$ \\
\hline & LHIN 4 Total & $25.5 \%$ & $29.2 \%$ & $34.1 \%$ \\
\hline 5 & LHIN 5 Total & $28.4 \%$ & $54.7 \%$ & $52.7 \%$ \\
\hline 6 & LHIN 6 Total & $15.1 \%$ & $18.6 \%$ & $16.7 \%$ \\
\hline \multirow[t]{6}{*}{7} & LHIN 7 community hospitals & $26.8 \%$ & $65.4 \%$ & $67.9 \%$ \\
\hline & Mount Sinai Hospital $^{2}$ & $47.1 \%$ & $62.1 \%$ & $74.5 \%$ \\
\hline & St. Michael's Hospital ${ }^{2}$ & $23.0 \%$ & $34.1 \%$ & $38.0 \%$ \\
\hline & $\begin{array}{l}\text { Sunnybrook and Women's College Health Sciences } \\
\text { Centre }^{a}\end{array}$ & $1.1 \%$ & $3.1 \%$ & $0.3 \%$ \\
\hline & University Health Network ${ }^{a}$ & $45.4 \%$ & $84.1 \%$ & $85.6 \%$ \\
\hline & LHIN 7 Total & $21.2 \%$ & $38.7 \%$ & $41.0 \%$ \\
\hline 8 & LHIN 8 Total & $24.0 \%$ & $54.1 \%$ & $65.3 \%$ \\
\hline 9 & LHIN 9 Total & $15.8 \%$ & $32.5 \%$ & $40.9 \%$ \\
\hline \multirow[t]{3}{*}{10} & LHIN 10 community hospitals & $17.0 \%$ & $71.6 \%$ & $79.7 \%$ \\
\hline & Kingston General Hospital ${ }^{2}$ & $0.3 \%$ & $15.8 \%$ & $22.7 \%$ \\
\hline & LHIN 10 Total & $8.9 \%$ & $44.6 \%$ & $49.6 \%$ \\
\hline \multirow[t]{4}{*}{11} & LHIN 11 community hospitals & $19.0 \%$ & $63.3 \%$ & $77.0 \%$ \\
\hline & Ottawa Hospital Corporation ${ }^{a}$ & $15.8 \%$ & $57.1 \%$ & $49.9 \%$ \\
\hline & Hopital Montfort ${ }^{2}$ & $9.8 \%$ & $71.0 \%$ & $85.8 \%$ \\
\hline & LHIN 11 Total & $15.5 \%$ & $61.7 \%$ & $64.8 \%$ \\
\hline 12 & LHIN 12 Total & $8.1 \%$ & $31.3 \%$ & $38.8 \%$ \\
\hline 13 & LHIN 13 Total & $0.2 \%$ & $20.2 \%$ & $35.6 \%$ \\
\hline \multirow[t]{2}{*}{14} & LHIN 14 Total & $1.1 \%$ & $36.9 \%$ & $53.5 \%$ \\
\hline & Ontario Total & $24.9 \%$ & $43.7 \%$ & $48.7 \%$ \\
\hline
\end{tabular}

${ }^{a}$ Academic medical centre; treated as a separate region 
Fig. 3 A schematic depicting the application of the OJRR prioritization guidelines to

9,268 patient records in the

OJRR database who received TJR between April 2002 and March 2005 and had responded to additional surveys of preoperative disability, patient role, and patient independence

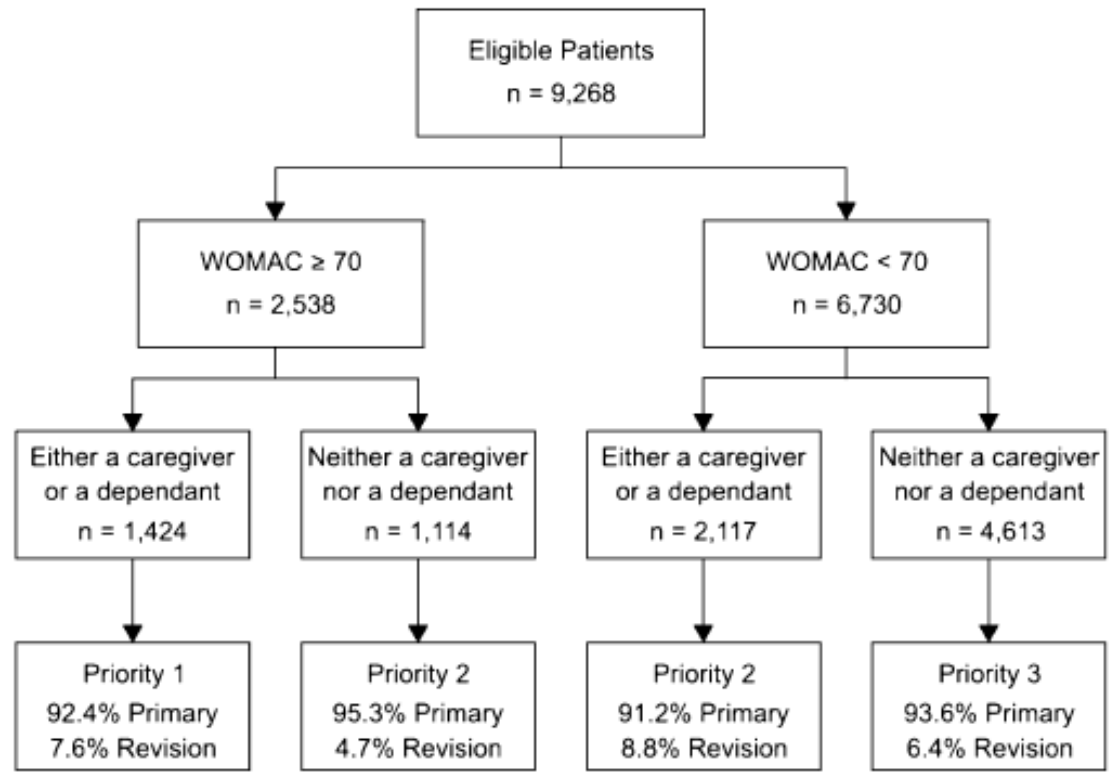

Increasing patient willingness to consider surgery at 5\% each year resulted in willingness in the 10th simulated year being approximately equal to the proportion of eligible individuals who described themselves as "definitely" and "probably" willing to consider surgery [87]. The actual rate that willingness will change is unknown but it is predicted to increase over time $[87,88]$. There are government programs in place trying to increase access to primary care and specialist services which may contribute to an increase in access to surgery as well [99].

The number of new decisions to have surgery in a specific month in the simulation $\left(N D_{i, m}\right)$ varied based on the pattern of new decisions observed in the OJRR database. Fewer decisions to have surgery are made in July, August, and December, consistent with vacation patterns. A multiplier representing monthly variation in the number of decisions for each LHIN $\left(D V_{i, m}\right)$ was selected from a table of historically observed variation around the mean monthly number of new decisions for that LHIN observed in 2004/ 2005. The number of new decisions to have surgery made by people living in LHIN i in month $\mathrm{m}$ was a function of the estimated mean number of new decisions estimated to occur each month in that fiscal year and the historically observed variation around the mean:

(5)

$$
N D_{i, m}=D_{i, n[m]} \times D V_{i, m} .
$$


Travel Across Regional Boundaries For Surgery

Patients may seek to have surgery or may be referred for surgical consultation outside of their own region. Individuals from each LHIN $\left(N D_{i, m}\right)$ were distributed to each region based on the patient travel patterns observed in 2004/2005. Thus,

$$
N P_{j, m}=\sum_{i=1}^{14} N D_{i, m} \times T_{i, j},
$$

where $T_{i, j}$ represented the proportion of patients from LHIN $i$ who received surgery in region $j$.

We ignored demand for TJR surgery from non-Ontario residents because it comprised less than $0.5 \%$ of total demand for TJR surgery in Ontario (99 of 28,998 records) and fewer than $0.1 \%$ of TJR surgeries provided to Ontario residents are provided by hospitals in another province [100].

Allocating the Provincial Volume of Surgeries Across Regions

We used two methods to estimate the number of surgeries available each month in each region $\left(A V_{j, m}\right.$, where $j=1, \ldots, 25$ and $\left.\mathrm{m}=0, \ldots, 120\right)$. In method 1 , the available number of surgeries was calculated as a direct function of the number of patients to join the waiting list for surgery in that region that month,

$$
A V_{j, m}=y \times N P_{j, m}
$$

This method was used to determine the behavior of the waiting list at fixed ratios of supply and demand.

In method 2, changes in supply are disconnected from changes in demand. The number of surgeries available across the province $\left(S_{n}\right)$ was determined as a function of the available surgeries in the previous year where

(8)

$$
S_{n}=S_{n-1} \times\left(1+r_{n}\right) \text {. }
$$

The annual supply of surgeries were subsequently allocated across regions to calculate the number of surgeries available $\left(A S_{j, n}\right)$, where 
(9)

$$
A S_{j, n}=A S_{j, n-1} \times a_{j, n} \times\left(S_{n}-S_{n-1}\right) .
$$

We considered scenarios in which the provincial rate of increase or decrease was uniform over all years of the scenario $\left(r_{n}=r_{n+1}\right)$, and also scenarios in which a high rate of increase was available in the first 1 or 2 years followed by a lower rate for the remaining years.

The current process of allocating surgeries across hospitals involves negotiation between the MOHLTC and the hospitals. The number of surgeries performed by each hospital each year is available retrospectively $[16,17]$, but the true method of allocation and the results of the negotiations (i.e., the number of surgeries that the MOHLTC was willing to fund) are not available. Due to the nature of the current allocation process, we were unable to replicate the historical pattern of allocating surgeries to regions. Thus, several allocation methods were analyzed, including those that allocated new funding on the basis of population rates of surgery; waiting times in the previous year; the number of decisions to have surgery in the previous year; and combinations of these factors.

In the base case, we used the following method to allocate surgeries to regions. In the first year of the simulation, representing $2005 / 2006$, the surgeries provided in excess of the number provided in $2004 / 2005$ were allocated across regions $j=1, \ldots, 25$ using the observed allocation of new surgeries between 2003/2004 and 2004/2005 $\left(a_{j, 0}=a_{j, 1}\right.$ where $a_{j, n}$ represents the proportion of new surgeries available across the entire province in year $n$ allocated to region $\mathrm{j}$ ). In each subsequent simulated year, regions were ranked based both on the number of new decisions to have surgery that were made in the previous year and the waiting time for surgery in months. The two ranks were then combined, with a weight of $70 \%$ applied to the waiting time rank and $30 \%$ applied to the number of new decisions rank. The top two ranked regions were each allocated $15 \%$ of new surgeries $\left(a_{j, n}=0.15\right)$; the next two were each allocated $10 \%$ of new surgeries; the following five regions were each allocated $5 \%$ of new surgeries; the following ten regions were each allocated $2.5 \%$ of new surgeries; the six regions with the lowest rank (best combined position of low waiting times and low demand for surgery) each received no additional surgeries. Except in scenarios in which the number of surgeries available to the entire province decreased, no region was allocated a decreasing amount of surgeries. We varied the allocation method to identify which system factors enabled the most efficient allocation of new surgical allocations. 
The Number of Surgeries Performed Each Month

The number of surgeries available each month varied based on the pattern of surgery dates observed in the OJRR database:

$$
A V_{j, m}=\frac{A S_{j, n[m]}}{12} \times S V_{j, m}
$$

Supply variation mimicked normal vacation patterns with fewer surgeries in the summer months and in December. Variation was simulated by randomly selecting a historical month's variation around the mean monthly supply for that region $\left(S V_{j, m}\right)$. Two hospitals did not have sufficient historical information to estimate monthly variation in supply; therefore the variation pattern was estimated based on a third similar hospital.

The final number of surgeries provided in a given month $\left(P S_{j, m}\right)$ was the lesser of the number of surgeries available in the month $\left(A V_{j, m}\right)$ and the total number of people waiting for surgery at the start of the month plus the number of new patients who joined the waitlist in that month:

$$
P S_{j, m}=\operatorname{Min}\left\{A V_{j, m}, W L_{j, m-1},+N P_{j, m}\right\} .
$$

When the number of patients waiting for surgery was less than the number of available surgeries, the number of available surgeries did not equal the number of surgeries provided. We assumed that unused surgery allocations could not be moved to another region. Thus, allocated but unused surgeries were lost.

\section{Assessing Queue Performance}

Queue performance indicators were collected at the end of each simulated year. The length of the waiting list at the end of the year, the number of patients who joined the list, the number of patients who were provided surgery, and the waiting time distribution including the proportion of patients who were provided surgery within specific time intervals $(1,3,6$, and 12 months) were recorded for all patients and for patient subgroups provided surgery in each region. 


\section{Results}

\section{Estimates of the Number of Patients Waiting for Surgery}

Using (1) to estimate the number of patients waiting at the two teaching hospitals and the average number of patients waiting on the last day of each month in 2004/2005 for the remaining regions, we estimate that the average number of patients who were waiting for TJR in Ontario on any given day between April 2004 and March 2005 was 27,145. The number of patients estimated to be waiting on the last day of each month increased over time; the average number of patients waiting at the end of each of the first 6 months was 24,627 whereas the average in the second half of the year was 29,662 patients waiting at the end of each month.

\section{Model Validating Scenarios: Fixed Ratios of Supply and Demand}

We tested the behavior of the model with some simple scenarios to ensure that the model would behave as predicted. We first considered scenarios in which the supply was a fixed proportion of demand. We considered supply equal to $50,75,100,110,125,150,175$, and $200 \%$ of demand. We considered demand growth rates of $0,5,8.5,10,12$, and $15 \%$ annually.

When supply was exactly equal to demand and demand did not increase over time, the proportion of patients who received surgery within each time interval ( 1 month, 3 months, 6 months, and 12 months) remained constant over time. When supply was exactly equal to demand and demand increased over time, the proportion of patients who received surgery within 6 months of their decision to have surgery increased. Figure 4 shows the proportion of patients that received surgery each year of the simulation within 6 months of the patient's decision to have surgery. For example, $80 \%$ of patients received surgery within 6 months of joining the waiting list in the simulated fiscal year 2009/ 2010 when supply exactly matched demand and demand for surgery increased at $15 \%$ each year. While the number of patients waiting for surgery at any time remains unchanged, the size of the waiting list relative to the number of surgeries available is decreasing. This increased throughput causes the probability of remaining on the list at the end of the month to decrease more rapidly with each passing month thus reducing waiting times.

When supply exceeded demand in each month by a fixed amount (when supply equaled 110, $125,150,175$, and $200 \%$ of demand), the proportion of patients receiving surgery within 6 months increased. Reductions in waiting times were observed regardless of the rate that demand increased. As 
expected, the marginal reduction in waiting times was greatest between $y=100$ and $y=110 \%$, and was smallest between $y=175$ and $y=200 \%$.

We estimated the $96 \%$ prediction interval by removing the two highest and two lowest estimates of the proportion of patients receiving surgery within 6 months at each point in time. This interval was smallest around predictions of low and high proportions of patients receiving surgery within 6 months and was widest around predictions of between 40 and $70 \%$ of surgeries provided within 6 months. At the widest point, the interval is approximately $+/-1$ year and $+/-20 \%$ of patients receiving surgery within 6 months.

\section{Surgical Volumes Required to Reduce Waiting Times}

For the remaining analysis, we estimated the number of new decisions using population projections that show an increase in the number of people over the age of 55, and the estimated future increase of $5 \%$ annually in patient willingness to consider surgery. In Ontario, the number of people over the age of 55 is estimated to increase by 36\% between 2005 and 2015 in the entire province [98]. The regions surrounding but not including LHIN 7 (LHINs 5, 6, 8, 9 and 12; see Fig. 1) currently contain onethird of the province's over age 55 population and are predicted to each experience increases ranging from 46 to $65 \%$ in the number of people over age 55 over the next 10 years. Including the expected increase in patient willingness, we estimated that the number of new decisions to have TJR surgery will increase at an average annual rate of $8.7 \%$ across the province, resulting in a total increase of $130 \%$ over 10 years. The projected increase in demand was not monotonic over the 10 -year period; the average rate of increase was 8.9\% each year over the first 6 years and lowered to 8.3\% each year from 2011 through to 2015. This is because demand is driven to a large extent by population growth, which is not monotonic over the horizon of our model. Table 4 provides the average annual rate of demand increase predicted for each region.

With this estimate of increasing demand and a time frame of 10 years, $12 \%$ more surgeries must be provided each year to ensure that $70 \%$ of TJR surgeries are provided within 6 months of the decision to have surgery. Providing more than a $12 \%$ annual increase in surgeries resulted in achieving this target earlier than 10 years (Fig. 5). For example, to provide $90 \%$ of primary TJRs within 6 months by 2014/2015, 14\% more surgeries must be available each year. 
Fig. 4 The proportion of primary total joint replacements received within 6 months of decision in each of six scenarios. The scenarios vary in the annual increase in the demand for surgeries

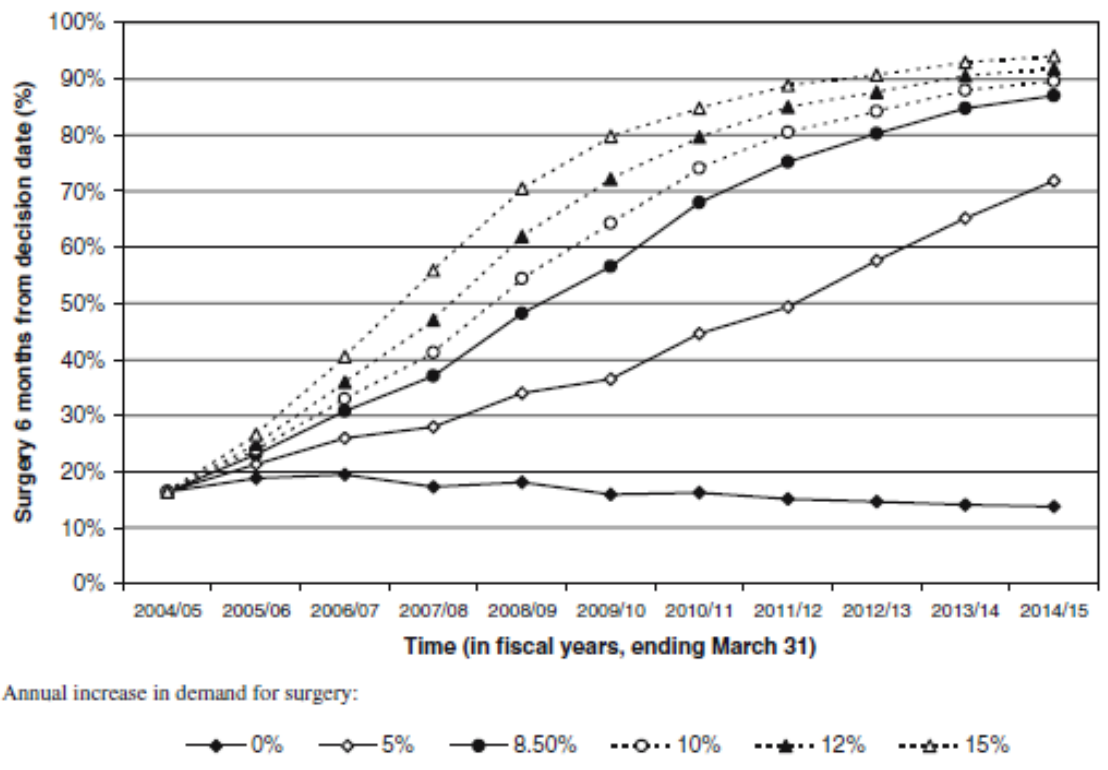

Providing a large increase in the number of surgeries performed each year in the short term followed by a lesser rate of increase in subsequent years could potentially condense the time frame for waiting time reductions. Depending on the rate of increase after the short term burst in supply, waiting times can be reduced on an accelerated time frame or the waiting time improvements that have been achieved can be lost. The former result is obtained when the subsequent rate continues to be greater than the rate at which demand is increasing (Fig. 6a); the latter result is obtained if the subsequent rate is less than the rate of demand growth (Fig. 6b).

\section{Queue Performance Considering Different Allocation Methods}

Allocating surgeries on the basis of the number of surgeries per person over the age of 20 in the LHIN resulted in short term improvement in the proportion of patients who received surgery within 6 months relative to the case where surgeries were allocated on the basis of waiting times in the different regions. However, this short-term gain was accompanied by increased regional disparity. In the longterm, distributing surgeries on the basis of waiting times or the number of new decisions to have surgery made in the previous year resulted in reduced regional disparity in waiting times and a greater overall reduction in waiting times.

Combining allocation methods resulted in greater reductions in waiting times in shorter time frames. In Fig. 7, four methods of allocating surgeries are shown: two that rank the regions using only one characteristic (the proportion of surgeries provided within 6 months of the decision date or the rate of surgeries per 100,000 population over age 20 ), and two that combine those characteristics with a 
second factor about the region (the number of new decisions to have surgery made in the previous simulated year). Adding a second factor provided a meaningful logic when choosing between two otherwise "tied" regions. Combining two proxies for need in the population (the proportion of surgeries provided within 6 months of the decision date and the number of new decisions to have surgery in the previous year) resulted in a slightly faster reduction in waiting times for primary TJR surgery compared to using waiting times alone.

\section{Sensitivity Analysis}

All sensitivity analysis described was performed assuming a $16 \%$ annual increase in the number of surgeries available each year so that the magnitude of the effects can be compared across analyses. Sensitivity analysis was performed at several other rates of increase in the number of surgeries performed annually and all observations were consistent with the trends presented here.

Eliminating the monthly variation in supply or in demand resulted in a maximum net change of less than 3\% in any year relative to the base case scenario in the proportion of planned primary TJRs provided within 6 months. We also evaluated the impact of a large sudden shift in travel patterns by using a modified travel matrix starting in the 37th month. Four modified tables were used, assessing the impact of 10 and $20 \%$ more patients and 10 and $20 \%$ fewer patients seeking care in their home region. In all cases, shifting travel patterns caused temporary reductions in the proportion of patients who received surgery within 6 months relative to the base case. However, this difference from the base case was eliminated within 3 years of the shift.

On the basis of non-overlapping 95\% confidence intervals around the mean proportion, only two factors affected the base case results. The first one was the number of patients waiting at the start of the simulation, which we varied by $+/-20 \%$ to ensure that all reasonable values were assessed. When there were only 21,235 patients waiting for TJR surgery at the beginning of the simulation, an average of $14.7 \%$ more surgeries were provided within 6 months of the patient's decision date each year for the first 5 years. When there were 31,489 patients waiting for TJR surgery, an average of $8.4 \%$ fewer surgeries each year were provided within 6 months relative to the base case for the first 5 years. 
Tahle 4 Predicted average amnul increase in TR surgary demand over 10 yaurs by region asaming patient tavel paterns nemin contsit over time

\begin{tabular}{|c|c|c|}
\hline LHIN & Region & $\begin{array}{l}\text { Avarage Armul Demand } \\
\text { Growth Rate 2004/2005 } \\
\text { tercugh 2014/2015 }\end{array}$ \\
\hline 1 & LHN 1 Total & $8.2 \%$ \\
\hline \multirow[t]{4}{*}{2} & $\begin{array}{l}\text { LHW } 2 \text { community } \\
\text { horspitals }\end{array}$ & $9.5 \%$ \\
\hline & $\begin{array}{l}\text { London Hanlth Sciences } \\
\text { Centre" }\end{array}$ & $9.4 \%$ \\
\hline & $\begin{array}{l}\text { St. Joreph's Health } \\
\text { Care, London" }\end{array}$ & $93 \%$ \\
\hline & LHN 2 Total & $9.4 \%$ \\
\hline 3 & LHN 3 Total & $9.5 \%$ \\
\hline \multirow[t]{4}{*}{4} & $\begin{array}{l}\text { LHN } 4 \text { ormmunity } \\
\text { horpitals }\end{array}$ & $7.4 \%$ \\
\hline & $\begin{array}{l}\text { Hamilan Henth } \\
\text { Sciences Corponation* }\end{array}$ & $4.0 \%$ \\
\hline & $\begin{array}{l}\text { St. Joreph's Heath } \\
\text { Care, Hamittona }\end{array}$ & $9.8 \%$ \\
\hline & LHN 4 Total & $6.1 \%$ \\
\hline 5 & LHN 5 Total & $8.2 \%$ \\
\hline 6 & LHN 6 Total & $11.2 \%$ \\
\hline \multirow[t]{6}{*}{7} & $\begin{array}{l}\text { LHN } 7 \text { commurity } \\
\text { horghitals }\end{array}$ & $10.8 \%$ \\
\hline & Mcrant Sinai Honģital" & $6.7 \%$ \\
\hline & St Michael's Hospital" & $15.3 \%$ \\
\hline & $\begin{array}{l}\text { Sunnybrocik and } \\
\text { Women's College } \\
\text { Health Sciences } \\
\text { Centre" }\end{array}$ & $6.5 \%$ \\
\hline & $\begin{array}{l}\text { University Heath } \\
\text { Newcrk }\end{array}$ & $11.4 \%$ \\
\hline & LHN 7 Total & $8.7 \%$ \\
\hline 8 & LHN \& Total & $10.3 \%$ \\
\hline 9 & LHN 9 Total & $10.0 \%$ \\
\hline \multirow[t]{3}{*}{10} & $\begin{array}{l}\text { LHN } 10 \text { community } \\
\text { horgitals }\end{array}$ & $9.4 \%$ \\
\hline & $\begin{array}{l}\text { Kingsta Geneal } \\
\text { Horsitar }\end{array}$ & $7.9 \%$ \\
\hline & LHN 10 Total & $8.6 \%$ \\
\hline \multirow[t]{4}{*}{11} & $\begin{array}{l}\text { LHN } 11 \text { community } \\
\text { horgstals }\end{array}$ & $10.5 \%$ \\
\hline & $\begin{array}{l}\text { Ottawa Hospital } \\
\text { Congcrsicn" }\end{array}$ & $8.0 \%$ \\
\hline & Hopital Monfort & $8.4 \%$ \\
\hline & LHN 11 Total & $8.6 \%$ \\
\hline 12 & LHN 12 Total & $11.4 \%$ \\
\hline 13 & LHN 13 Toal & $6.1 \%$ \\
\hline \multirow[t]{2}{*}{14} & LHN 14 Toal & $6.2 \%$ \\
\hline & Ontario Toal & $8.7 \%$ \\
\hline
\end{tabular}

"Academic medical centre; treated as a separse regicn 
The second factor that significantly affected the base case results was the annual increase in the demand for surgeries. We varied this factor widely from annual rates of $3.4 \%$, a scenario which assumed that willingness to consider surgery would not increase, to $13.9 \%$, a scenario which assumed that willingness to consider surgery would increase at $10 \%$ each year. Consistent with our observations for fixed supply and demand ratios, whenever the actual number of surgeries was less than the number of surgeries demanded, the proportion of patients who received surgery within 6 months of decision decreased. When willingness was assumed to increase at 2.5\% per year (which results in demand increasing at a total rate of approximately $6 \%$ each year) reaching a target of $90 \%$ of patients receiving surgery within 6 months occurs 1 year sooner than in the base case. Conversely, when willingness to undergo surgery increases at $7.5 \%$ per year (which results in demand increasing at a total rate of approximately $11.3 \%$ each year) reaching the same target of $90 \%$ of patients receiving surgery within 6 months occurs 2 years later than in the base case.

\section{Discussion}

In this paper we describe a queuing model that considers non-homogeneous projections of demographic trends [97] and inter-regional travel patterns for surgery to determine the number of surgeries that are required to meet clinically relevant waiting time targets. The model was built by aggregating data from more than 250 queues maintained by individual surgeons into 25 regional queues. In very broad terms, some of the conclusions could be made on the basis of well-known results in queuing theory. For example, even if demand does not increase over the next 10 years, providing the same number of surgeries as were provided in 2004/2005 will cause waiting times for surgery to increase and even if supply increases but the current supply to demand ratio (approximately 0.75 ) is maintained in each year, waiting times for surgery will continue to increase. The simulation model described in this paper allows us to go beyond these very general results to estimate how many surgeries are required to meet waiting time objectives considering demand projections specific to Ontario. By aggregating into regional queues, we have been able to identify the waiting time consequences of some specific allocation policies. We are not aware of any other effort of this nature being completed in Ontario. 
Fig. 5 The proportion of primary total joint replacements received within 6 months of decision in each of seven scenarios. The scenarios vary in the annual increase in the number of surgeries available

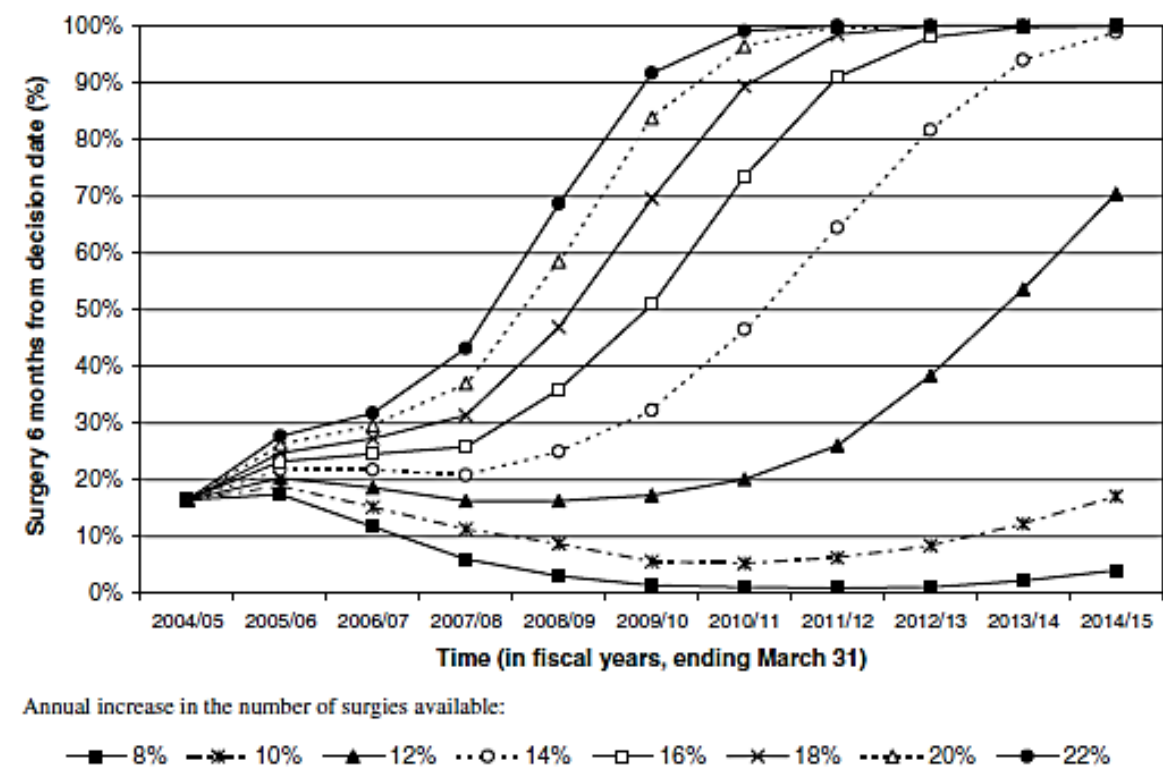

We estimate that in order to achieve a target of completing $90 \%$ of primary TJR surgeries within 6 months of the decision for surgery in a time horizon of 5 years, surgical capacity must increase at 22\% for 3 years, followed by a rate that continues to ensure that supply exceeds demand. To complete $90 \%$ of surgeries within 6 months of the decision for surgery in a time horizon of 7 years, surgical capacity must increase by $16 \%$ per year for 4 years, followed by a rate that ensures that supply continues to exceed demand. This is substantially higher than the $6 \%$ average annual increase in surgeries provided between 1995/1996 and 2003/2004 [16].

We also identified that allocating surgeries on a population basis as recommended by the Total Hip and Knee Replacement Expert Panel [21] will result in greater regional disparity in waiting times. Ontario, like many other Canadian provinces, is now posting retrospectively collected waiting times online [101]. It is believed that if waiting time information is known, then patients will choose regions with smaller waiting times [9]. There has been no formal testing of the benefits or consequences of this policy so it is uncertain whether posting waiting times and the potential subsequent patient selection of surgeons with shorter waiting times will reduce the regional disparity allocating by population size will create.

Human resource shortages have been identified in orthopedics [102, 103], anesthesiology [104106], nursing [107], and other critical areas, indicating that the large increases in surgical volumes required to reduce waiting times will be a formidable challenge to policy makers. Because each hospital may have different factors limiting growth in surgical capacity, surgical volumes must be added in a 
coordinated fashion. Evidence of the importance of targeted and coordinated growth in capacity has been observed in both real [108] and simulated [35] situations.

The effects of increasing surgical volumes without knowing of the extent of unmet need was demonstrated in Denmark and England [109]. Denmark, with relatively high capacity, managed to sustain reduced waiting times by further increasing capacity. England, with relatively low capacity and long waiting times, experienced longer waiting times when capacity was increased because the number of surgeries provided still did not match demand. Thus, the effectiveness of strategies that only impact supply may depend on the extent of the waiting time problem. If there is a small supply shortage, additional supply may solve the problem, but if there is a large supply shortage and a large unmet need, then a very large supply increase may be required to generate reductions in waiting times. There may be a large unmet need for total joint replacement in Ontario $[27,47,87,110]$. Reflecting on the results of this analysis and the experiences of other jurisdictions, Ontario must consider that additional supply alone may not result in sustained reductions in waiting times. Other policy options, specifically those that may reduce demand, should be considered.

Fig 6 The proportion of primary total joint replacements received within 6 months of decision in each of six scenarios The scenarios vary in the annual increase in the number of surgeries available

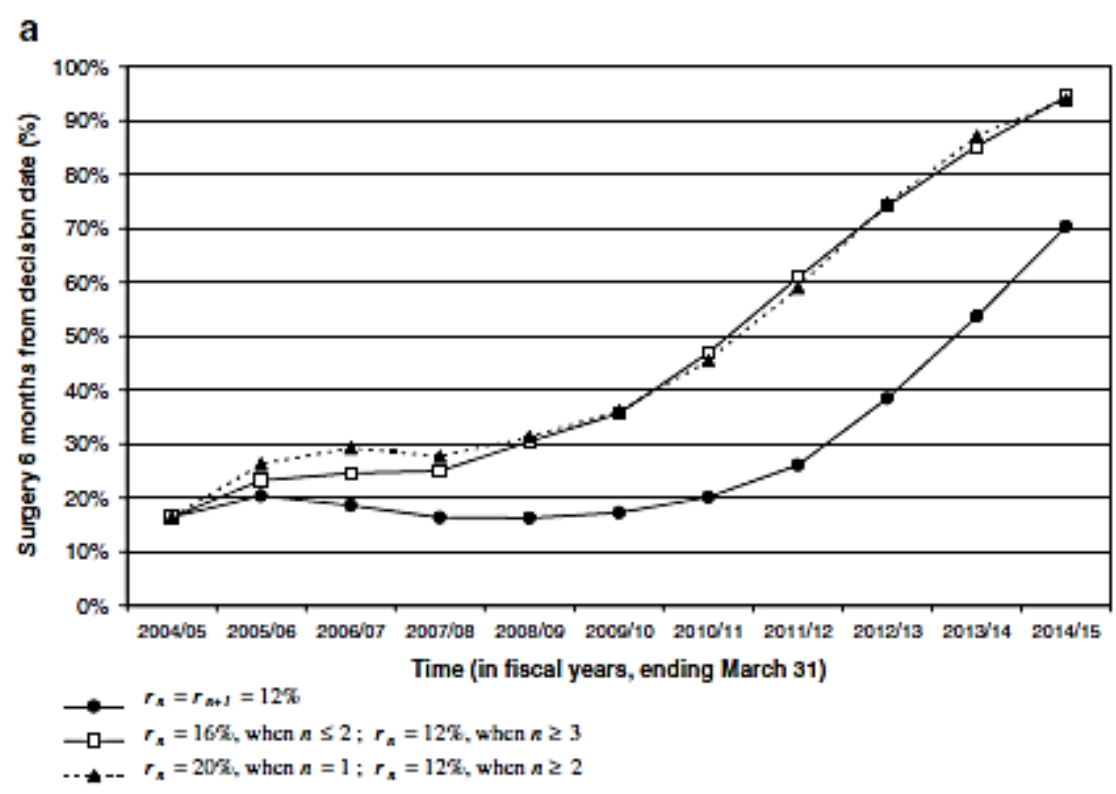




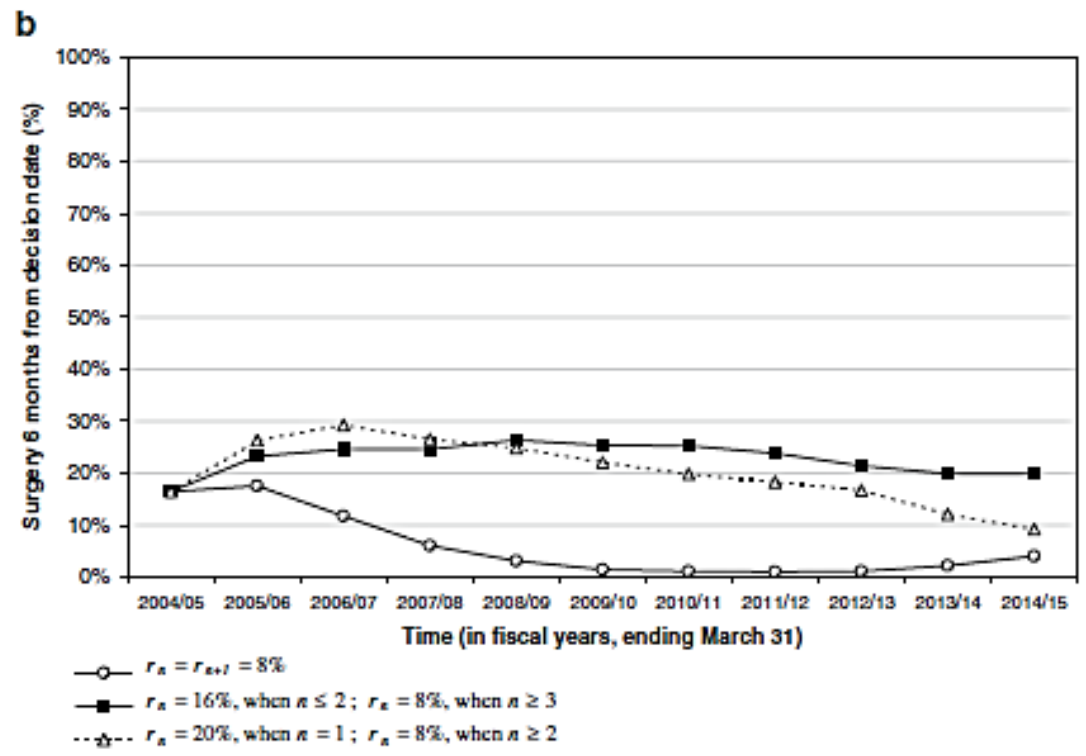

The lessons learned from this simulation may be applicable to other areas dealing with excessive waiting times. For example, with some elective surgery procedures there is no increased mortality associated with delayed care. Thus, it is necessary to evaluate the proportion of patients that receive surgery within clinically important thresholds. When waiting times become unacceptable to patients and clinicians, simulation modeling can assist decision makers in determining how many additional surgeries are required and where to allocate them so that waiting times can be reduced quickly and efficiently. We have shown that the benefits of special targeted funding to reduce waiting times can be lost if long term rates of supply increase are not greater than the rate of patients joining the waiting list. We are not aware of others who have modeled a short term burst in capacity as a potential solution to waiting time problems. 
Fig. 7 The proportion of primary total joint replacements received within 6 months of decision in each of four scenarios. The scenarios vary in the method of determining $a_{j, n}$

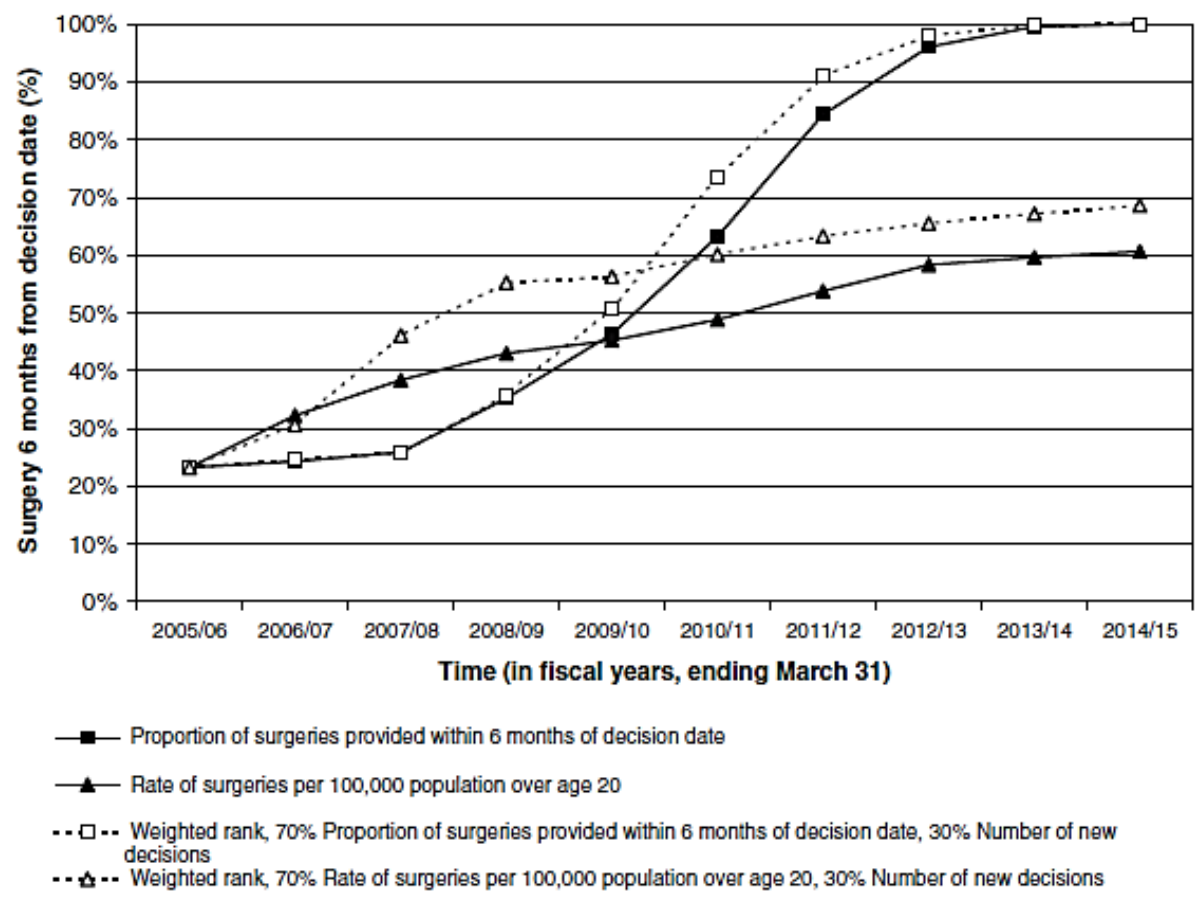

The model developed here is a high-level simplification of a highly complex system. We simulated at the regional level rather than at the level of each hospital or individual surgeons. Due to the voluntary nature of data submission to the OJRR, the completeness of surgeon level data varied widely. Only the surgeons hold accurate surgeon-level data with respect to the waiting times and casemix of severity for their patients, and while participation of all surgeons was a long-term goal of the OJRR, complete surgeon level information was not available when the simulation was developed. While all efforts were made to simulate the current situation, the behaviors of all patients and surgeons, the specific capacity limitations faced by each hospital and each region, and other confounding factors were not included. In the simulated allocation process, we may have allocated surgical volumes to some regions that currently may not be feasible to complete.

There are also limitations in the primary data. The OJRR dataset does not represent a random sampling of surgeries in the province due to self-selection of participating surgeons. However, no other source was available to validate these model parameters. The OJRR dataset was used to estimate the number of patients currently waiting, rates of demand, and patient travel patterns and two assumptions we made about the OJRR data may have affected these estimates: (1) we assumed that the registry data accurately represented the patient characteristics, travel patterns, and waiting times of all patients based on the fiscal year they received surgery; (2) we assumed that patients who had not yet received surgery were representative of waiting patients based on the fiscal year they decided to have surgery. 
We conducted extensive sensitivity analysis on all model parameters to identify which parameters cause significant shifts in the waiting time predictions.

We have been able to estimate how many surgeries will need to be performed each year to meet current waiting time objectives. We have not, however, identified the best method for increasing the volume of surgeries performed each year. Many suggestions have been put forth with respect to how more surgeries will be provided including recommendations for the reorganization of current resources and practices [21]; others have suggested that without additional resources the alleviation of waiting times in the current target areas may come at the expense of other health care services [18]. We did not evaluate the consequences of different funding and service delivery options in this work because this would have required detailed information about the resource usage and constraints in every Ontario hospital but we plan to evaluate the potential consequences of some waiting time strategies such as waiting time guarantees in future work. In addition, we did not consider the deterioration in quality of life or the possible reductions in the benefits of surgery that may occur due to waiting for surgery. Future research may incorporate decay functions for both quality of life and benefits of surgery into waiting time models if a good understanding of such functions becomes available.

The only factor that the base case model is sensitive to is demand, including both the current number of patients waiting and projections of future demand. A wide range of demand predictions were tested here, but the actual demand for surgery over the next 10 years remains unknown. There are currently no systems for tracking the underlying need for TJR surgery in the province or the number of new decisions to join a waiting list, nor is the actual number of patients currently waiting for surgery in Ontario known. This study identifies the critical importance of knowing demand, and thus identifies a critical shortfall of the current Ontario total joint replacement system that must be addressed to ensure that neither a shortage of supply nor an excess of waste, through excess allocations, occur in the future.

\section{References}

Harris WH, Sledge CB (1990) Total hip and total knee replacement (1). N Eng J Med 323(11):725-731 (2003) NIH consensus statement on total knee replacement. NIH Consensus State of the Science Statements. 20(1):1-32

Harris WH, Sledge CB (1990) Total hip and total knee replacement (2). N Eng J Med 323(12):801-807

Brauer CA, Rosen AB, Olchanski NV, Neumann PJ (2005) Cost-utility analyses in orthopedic surgery. J Bone JT Surg [Am Vol] 87(6):1253-1259 
Laupacis A, Bourne R, Rorabeck C, Feeny D, Wong C, Tugwell P, Leslie K, Bullas R (1994) Costs of elective total hip arthroplasty during the first year. Cemented versus noncemented. J Arthroplast 9(5):481-487

Lavernia CJ, Guzman JF, Gachupin-Garcia A (1997) Cost effectiveness and quality of life in knee arthroplasty. Clin Orthop Relat Res (345):134-139

Brunenberg DE, van Steyn MJ, Sluimer JC, Bekebrede LL, Bulstra SK, Joore MA (2005) Joint recovery programme versus usual care: an economic evaluation of a clinical pathway for joint replacement surgery. Med Care 43(10):1018-1026

Chang RW, Pellisier JM, Hazen GB (1996) A cost-effectiveness analysis of total hip arthroplasty for osteoarthritis of the hip. J Am Med Assoc 275(11):858-865

Blake JT (2005) Shooting arrows in the dark: the policies and practices of waitlist management in Canada. Clin Invest Med 28 (6):308-311

Coyte PC, Wright JG, Hawker GA, Bombardier C, Dittus RS, Paul JE, Freund DA, Ho E (1994) Waiting times for knee-replacement surgery in the United States and Ontario. N Eng J Med 331(16):106810671

Health care professionals views on access to health care (2004) [cited 2006, February 14]; Available from: http://www.cma.ca/multimedia/staticcontent/CMA/Content_Images/Inside_cma/ Better-Access/Ipsos-Polling.pdf

Chaoulli v. Quebec (Attorney General), 2005 scc35 (2005) 1 Supreme Court Reports 791

Williams JI, Shipton D, Badley EM, Hawker G, Kreder HJ, DeBoer D, Guan J, Mahomed N (2004) Surgical Services. In: Badley EM, Glazier R (eds) Arthritis and related conditions in Ontario: ICES research atlas. Institute for Clinical Evaluative Sciences, Toronto, ON

Esmail N, Walker M (2004) Waiting your turn: hospital waiting lists in Canada. 14th ed. Critical Issues Bulletin: Fraser Institute, Vancouver, BC

Noseworthy T, McGurran J, Hadorn D (2003) Waiting for scheduled services in Canada. J Eval Clin Pract 9(1):23-31

Bourne RB, DeBoer D, Hawker GA, Kreder HJ, Mahomed NN, Paterson JM, Warner S, Williams JI (2005) Chapter 5. Total hip and knee replacement. In: Tu JV et al (eds) Access to Health Services in Ontario: ICES Atlas. Institute for Clinical Evaluative Sciences, Toronto, ON

Bourne RB, DeBoer D, Hawker GA, Kreder HJ, Laupacis A, Mahomed NN, Paterson JM, Pinfold SP, Warner S, Williams JI (2006) Chapter 5. Total hip and knee replacement. In: Tu JV et al (eds) 
Access to Health Services in Ontario: ICES Atlas Update. Institute for Clinical Evaluative Sciences, Toronto, ON

Wait Time Alliance for Timely Access to Health Care (2005) It's about time! Achieving benchmarks and best practices in wait time management. Canadian Medical Association, Ottawa, ON. Available from:http://www.waittimealliance.ca/multimedia/CMA/Content_Images/Inside_cma/Media_Re lease/pdf/2005/ wta-final.pdf

First ever common benchmarks will allow Canadians to measure progress in reducing wait times. [Press Release, December 12, 2005] Available from: http://www.health.gov.on.ca/english/me dia/news_releases/archives/nr_05/nr_121205.html

Chesworth B, Warner S, Bourne R (2006) Guideline for wait time thresholds for total hip and knee replacement surgery based on severity: Detailed report. Ontario Joint Replacement Registry, London, ON

Gross AE (2005) Report of the total hip and knee joint replacement expert panel. Total Hip and Knee Joint Replacement Expert Panel. Available from: http://www. health.gov.on.ca/renouvellement/wait_timesf/wt_reportsf/hip_knee_ep_report_0905.pdf

Bunker JP, Frazier HS, Mosteller F (1994) Improving health: measuring effects of medical care. Milbank Q 72(2): 225-258

(2003) Total Joint Replacements in Ontario: First Edition. Ontario Joint Replacement Registry, London, ON

Chesworth B, Warner S, Bourne R (2004) Total joint replacements in ontario: Annual Report 2004. Ontario Joint Replacement Registry, London, ON

Perruccio AV, Badley EM, Guan J (2004) Burden of disease. In: Badley EM, Glazier R (eds) Arthritis and related conditions in Ontario: ICES research atlas. Institute for Clinical Evaluative Sciences, Toronto, ON

(1994) NIH consensus statement on total hip replacement. NIH Consensus State of the Science Statements 12(5):1-31

Hawker GA, Wright JG, Coyte PC, Williams JI, Harvey B, Glazier R, Badley EM (2000) Differences between men and women in the rate of use of hip and knee arthroplasty. N Eng J Med 342(14):10161022

Hawker GA (2004) The quest for explanations for race/ethnic disparity in rates of use of total joint arthroplasty. J Rheumatol 31 (9):1683-1685 
Hawker GA, Wright JG, Glazier RH, Coyte PC, Harvey B, Williams JI, Badley EM (2002) The effect of education and income on need and willingness to undergo total joint arthroplasty. Arthritis Rheum 46(12):3331-3339

Karlson EW, Mandl LA, Aweh GN, Sangha O, Liang MH, Grodstein F (2003) Total hip replacement due to osteoarthritis: the importance of age, obesity, and other modifiable risk factors. Am J Med 114(2):93-98

Gelber AC, HochbergMC, Mead LA, Wang NY, Wigley FM, Klag MJ (1999) Body mass index in young men and the risk of subsequent knee and hip osteoarthritis. Am J Med 107(6):542-548

Jarvholm B, Lewold S, Malchau H, Vingard E (2005) Age, bodyweight, smoking habits and the risk of severe osteoarthritis in the hip and knee in men. Eur J Epidemiol 20(6):537-542

Katzmarzyk PT (2002) The Canadian obesity epidemic, 1985- 1998. Can Med Assoc J 166(8):1039-1040

Katzmarzyk PT (2002) The Canadian obesity epidemic: an historical perspective. Obes Res 10(7):666-674

Dunbar MJ, Malloy L, Blake JT, Hennigar A, Storey J (2004) Department of surgery, wait list management project, orthopedic pilot project. Queen Elizabeth II Health Sciences Center, Halifax, NS

Robertsson O, Dunbar MJ, Knutson K, Lidgren L (2000) Past incidence and future demand for knee arthroplasty in Sweden: a report from the Swedish Knee Arthroplasty Register regarding the effect of past and future population changes on the number of arthroplasties performed. Acta Orthop Scand 71(4):376-380

Brander VA, Malhotra S, Jet J, Heinemann AW, Stulberg SD (1997) Outcome of hip and knee arthroplasty in persons aged 80 years and older. Clin Orthop Relat Res (345):67-78

Derrett S, Paul C, Morris JM (1999) Waiting for elective surgery: effects on health-related quality of life. Int J Qual Health Care 11 (1):47-57

Lillard LA, Rogowski J, Kington R (1999) Insurance coverage for prescription drugs: effects on use and expenditures in the Medicare population. Med Care 37(9):926-936

Kington R, Rogowski J, Lillard L (1995) Dental expenditures and insurance coverage among older adults. Gerontologist 35 (4):436-443

Poisal JA, Chulis GS (2000) Medicare beneficiaries and drug coverage. Health Aff (Millwood) 19(2):248256

Stuart B, Doshi JA, Briesacher B, Wrobel MV, Baysac F (2004) Impact of prescription coverage on hospital and physician costs: a case study of medicare beneficiaries with chronic obstructive pulmonary disease. Clin Ther 26(10):1688-1699 
Coulson NE, Terza JV, Neslusan CA, Stuart BC (1995) Estimating the moral-hazard effect of supplemental medical insurance in the demand for prescription drugs by the elderly. Am Econ Rev 85(2):122126

Poisal JA, Murray L (2001) Growing differences between Medicare beneficiaries with and without drug coverage. Health Aff (Millwood) 20(2):74-85

Cross MJ, March LM, Lapsley HM, Tribe KL, Brnabic AJ, Courtenay BG, Brooks PM (2000) Determinants of willingness to pay for hip and knee joint replacement surgery for osteoarthritis. Rheumatology 39(11):1242-1248

Hadley J, Cunningham PJ (2005) Perception, reality and health insurance: uninsured as likely as insured to perceive need for care but half as likely to get care. Issue Brief (Centre for Studying Health System Change) (100):1-5

Hawker GA, Wright JG, Badley EM, Coyte PC (2004) Perceptions of, and willingness to consider, total joint arthroplasty in a population-based cohort of individuals with disabling hip and knee arthritis. Arthritis Rheum 51(4):635-641

Bloom BS, Fendrick AM (1987) Waiting for care. Queuing and resource allocation. Med Care 25(2):131139

Williams Jl, Llewellyn Thomas H, Arshinoff R, Young N, Naylor CD (1997) The burden of waiting for hip and knee replacements in Ontario. Ontario Hip and Knee Replacement Project Team. J Eval Clin Pract 3(1):59-68

Rigge M (1994) Quality of life of long wait orthopedic patients before and after admission: a consumer audit. Qual Health Care 3(3):159-163

Thomas S, Ord J, Pailthorpe C (2001) A study of waiting time for surgery in elderly patients with hip fracture and subsequent in-patient hospital stay. Ann R Coll Surg Engl 83(1):37-39

Mahon JL, Bourne RB, Rorabeck CH, Feeny DH, Stitt L, Webster-Bogaert S (2002) Health-related quality of life and mobility of patients awaiting elective total hip arthroplasty: a prospective study. Can Med Assoc J 167(10):1115-1121

Roy CW, Hunter J (1996) What happens to patients awaiting arthritis surgery? Disability and Rehabilitation 18(2):101-105

Ostendorf M, Buskens E, van Stel H, Schrijvers A, Marting L, Dhert W, Verbout A (2004) Waiting for total hip arthroplasty: avoidable loss in quality time and preventable deterioration. J Arthroplast 19(3):302-309 
Rossvoll I, Benum P, Bredland TR, Solstad K, Arntzen E, Jorgensen S (1993) Incapacity for work in elective orthopedic surgery: a study of occurrence and the probability of returning to work after treatment. J Epidemiol Community Health 47(5):388-394

Hertzman P, Johnsson R, Lindgren B (1988) Cost of sick leave for total hip replacement. Acta Orthop Scand 59(3):266-269

Johnsson R, Persson BM (1986) Occupation after hip replacement for arthrosis. Acta Orthop Scand 57(3):197-200

Hajat S, Fitzpatrick R, Morris R, Reeves B, Rigge M, Williams O, Murray D, Gregg P (2002) Does waiting for total hip replacement matter? Prospective cohort study. J Health Serv Res Policy 7(1):19-25

Health Canada: Wait times in Canada. [cited 2006, February 24]; Available from: http://www.hcsc.gc.ca/hcs-sss/qual/acces/ wait-attente/index_e.html

Kingman JFC (1962) On Queues in Heavy Traffic. J R Stat Soc, B (Methodological) 24(2):383-392

Kingman JFC (1962) Some inequalities for the queue GI/G/1. Biometrika 49(3/4):315-324

Kollerstrom J (1974) Heavy traffic theory for queues with several servers. I. J Appl Probab 11(3):544-552

Mazumdar S (1970) On priority queues in heavy traffic. J R Stat Soc, B (Methodological) 32(1):111-114

Iglehart DL, Whitt W (1970) Multiple channel queues in heavy traffic. I. Adv Appl Probab 2(1):150-177

Whitt W (1972) Complements to heavy traffic limit theorems for the GI/G/1 queue. J Appl Probab 9(1):185-191

Dagsvik J (1979) Stability and heavy traffic results for the general bulk queue. Adv Appl Probab 10(1):213-231

Bindman AB, Grumbach K, Keane D, Rauch L, Luce JM (1991) Consequences of queuing for care at a public hospital emergency department. J Am Med Assoc 266(8):1091-1096

Ben-Haim M, Carmiel M, Katz P, Shabtai E, Oren R, Nakache R (2006) Is the model of end-stage liver disease (MELD) valid in Israel? A critical analysis of liver transplant waiting list mortality. Israel Med Assoc J 8(9):605-609

Navarro V (1969) A systems approach to health planning. Health Serv Res 4(2):96-111

Navarro V (1969) Planning personal health services: a Markovian model. Med Care 7(3):242-249

Navarro V, Parker R, White K (1970) A stochastic and deterministic model of medical care utilization. Health Serv Res 5(4):342-357

France DJ, Levin S (2006) System complexity as a measure of safe capacity for the emergency department. Acad Emerg Med 13(11):1212-1219 
Codrington-Virtue A, Whittlestone P, Kelly J, Chaussalet T (2005) An interactive framework for developing simulation models of hospital accident and emergency services. Stud Health Technol Inform 114:277-283

Gupta D, Natarajan MK, Gafni A, Wang L, Shilton D, Holder D, Yusuf S (2006) Capacity planning for cardiac catheterization: A case study. Health Policy, in press

Kaplan EH, Johri M (2000) Treatment on demand: an operational model. Health Care Manage Sci 3(3):171-183

Segev DL, Gentry SE, Melancon JK, Montgomery RA (2005) Characterization of waiting times in a simulation of kidney paired donation. American Journal of Transplantation 5 (10):2448-2455

Thompson D, Waisanen L, Wolfe R, Merion RM, McCullough K, Rodgers A (2004) Simulating the allocation of organs for transplantation. Health Care Manage Sci 7(4):331-338

Bruni ME, Conforti D, Sicilia N, Trotta S (2006) A new organ transplantation location-allocation policy: a case study of Italy. Health Care Manage Sci 9(2):125-142

Su X, Zenios SA, ChertowGM(2004) Incorporating recipient choice in kidney transplantation. J Am Soc Nephrol 15(6):1656-1663

Worthington DJ (1987) Queueing models for hospital waiting lists. J Oper Res Soc 38(5):413-422

Smith-Daniels V, Schweikhart S, Smith-Daniels D (1988) Capacity management in health care services: review and further research directions. Decis Sci 19(4):889-918

Klein RW, Dittus RS, Roberts SD, Wilson JR (1993) Simulation modeling and health-care decision making. Med Decis Mak 13 (4):347-354

Vissers JM (1998) Health care management modelling: a process perspective. Health Care Manage Sci $1(2): 77-85$

Jun J, Jacobson S, Swisher J (1999) Application of discrete-event simulation in health care clinics: a survey. JOper Res Soc 50:109-123

Local Health Integration Networks. (2004) October 2004 [cited 2006, February 17]; Available from: http://www.health.gov.on. ca/transformation/lhin/100604/att_1_100604.pdf

Law AM, Kelton WD (1982) Simulation modeling and analysis. McGraw-Hill, New York

Hawker GA, Wright JG, Coyte PC, Williams JI, Harvey B, Glazier R, Wilkins A, Badley EM (2001) Determining the need for hip and knee arthroplasty: the role of clinical severity and patients' preferences. Med Care 39(3):206-216

Hawker GA (2005) Personal Communication 
Arnett G, Hadorn DC (2003) Developing priority criteria for hip and knee replacement: results from the Western Canada Waiting List Project. Can J Surg 46(4):290-296

Noseworthy TW, McGurran JJ, Hadorn DC (2003) Waiting for scheduled services in Canada: development of priority-setting scoring systems. J Eval Clin Pract 9(1):23-31

Moving forward: final report. Western Canada Waiting List Project. Calgary, AB. Available from: http://www.wcwl.org/media/pdf/news/moving_forward/report.pdf

Rumble T, Kreder HJ (2005) Report of benchmarks for wait times. The National Standards Committee, Canadian Orthopaedic Association.

Report of the Provincial Wait Time Monitoring Project Steering Committee. (2004) [cited February 22, 2006]; Available from: http://www.gov.ns.ca/health/wait_times/full-Wait\%20Time.pdf

Target Time Frames For Surgery. [cited 2006, February 22]; Available from: http://www.sasksurgery.ca/target_timeframes.htm

Noseworthy T, Sanmartin C, Bohm E, Conner-Spady B, DeCoster C, Dunbar M, Lorenzetti D, McLaren L, McGurran J (2005) Towards establishing evidence-based benchmarks for acceptable waiting times for joint replacement surgery. Canadian Institute for Health Research, Toronto, ON

Bellamy N, Buchanan WW, Goldsmith CH, Campbell J, Stitt LW (1988) Validation study of WOMAC: a health status instrument for measuring clinically important patient relevant outcomes to antirheumatic drug therapy in patients with osteoarthritis of the hip or knee. J Rheumatol 15(12):1833-1840

Ontario Population Projections 2004-2031. (2005) Ontario Ministry of Finance [cited 2006, February 8]; Available from: http://www.fin.gov.on.ca/english/demographics/demog05.html

Local health integration networks: geographic boundaries and supporting information. (2006) May 2006 [cited 2006, June 28]; Available from: http://www.health.gov.on.ca/transformation/lhin/ Ihinmap_mn.html

(2006) Health care renewal in Canada: clearing the road to quality. Health Council of Canada, Toronto, ON

(2005) 2005 CJRR report: total hip and knee replacements in Canada. Canadian Joint Replacement Registry. Canadian Institute for Health Information, Toronto, ON

Wait times in Ontario. February 6, 2006 [cited 2006, February 10]; Available from: http://www.health.gov.on.ca/transformation/wait_times/wait_mn.html

Rumble T, Kreder HJ (2004) National Workforce \& Services Report. The National Standards Committee of the Canadian Orthopaedic Association. 
Shipton D, Badley EM, Mahomed NN (2003) Critical shortage of orthopedic services in Ontario, Canada. J Bone Jt Surg [Am Vol] 85-A(9):1710-1715

Byrick RJ, Craig D, Carli F (2002) A physician workforce planning model applied to Canadian anesthesiology: assessment of needs. Can J Anaesth 49(7):663-670

Craig D, Byrick R, Carli F (2002) A physician workforce planning model applied to Canadian anesthesiology: planning the future supply of anesthesiologists. Can J Anaesth 49(7):671-677

Engen DA,Morewood GH, Ghazar NJ, Ashbury T, VanDenKerkhof EG, Wang L (2005) A demand-based assessment of the Canadian anesthesia workforce-2002 through 2007. Can J Anaesth 52 (1):18-25

O'Brien-Pallas L, Alksnis C, Wang S (2003) Bringing the future into focus: projecting RN retirement in Canada. Canadian Institute for Health Information, Toronto, ON

Aiono S, Faber RG, Galland RB (2000) Surgeons have little control over general surgical waiting lists. Ann R Coll Surg of Engl 82(9 Suppl):304-307

Hurst J, Siciliani L (2003) OECD Health Working Papers No. 6: Tackling excessive waiting times for elective surgery: a comparison of policies in twelve OECD countries. Directorate for Employment, Labour, and Social Affairs, Paris

Wright JG, Hawker GA, Bombardier C, Croxford R, Dittus RS, Freund DA, Coyte PC (1999) Physician enthusiasm as an explanation for area variation in the utilization of knee replacement surgery. Med Care 37(9):946-956 